\title{
Monteiro lobato E A Mitologia gregA
}

\author{
Vitor Amaro Lacerda* \\ Colégio Santa Maria
}

\begin{abstract}
RESUMO
Este trabalho pretende observar as várias referências à mitologia grega na obra infantil de Monteiro Lobato e compreender qual o papel da apropriação deste repertório no conjunto geral de sua obra. Além de ser importante para a educação de seus jovens leitores, a mitologia grega é vista como a base a partir da qual a cultura grega se desenvolveu e atingiu seu apogeu no século $\mathrm{V}$ a.C., oferecendo um exemplo histórico das possibilidades de progresso cultural nacional a partir da mitologia brasileira.
\end{abstract}

\section{PALAVRAS - CHAVE}

Monteiro Lobato, mitologia grega, literatura infantil

Para a maior parte dos críticos, Monteiro Lobato é considerado o fundador da verdadeira literatura infantil brasileira, já que sua obra teria representado uma ruptura em relação ao momento anterior da história deste campo literário destinado às crianças. ${ }^{1}$ Certamente, um dos aspectos mais marcantes desta ruptura é a forma como suas histórias dialogam com outras tradições literárias. Já em Reinações de Narizinho, primeiro livro de sua coleção para crianças, percebe-se esta característica quando o célebre grupo do Sítio do Pica-pau Amarelo (Dona Benta, Tia Nastácia, Narizinho, Pedrinho, Emília e Visconde de Sabugosa) recebe visitas dos personagens do chamado "País das Maravilhas", um espaço que reúne histórias de origens diversas. Dentre os convidados para o chá da tarde no Sítio, podemos citar Cinderela, Branca de Neve, Pequeno Polegar, Capinha Vermelha e o lobo, Ali Babá, Gato de Botas, Peter Pan, Aladino, Barba-Azul, Rosa Vermelha e Rosa Branca, Patinho Feio, Hansel e Gretel, Xerazade, Codadad, Ahmed, Sinbad, Pássaro Roca, Pinóquio, Raggedy Ann.

Por outro lado, nesta mesma obra o grupo do Sítio realiza suas próprias viagens, com ou sem o "Pó de Pirlimpimpim", seja para o "Reino das Águas Claras" ou seja para

\footnotetext{
*vitoramaro@gmail.com

${ }^{1}$ Marisa Lajolo, por exemplo, uma das autoras mais importantes na análise da obra de Lobato, afirma que, com o Sítio do Pica-pau Amarelo, "Monteiro Lobato inaugura a literatura infantil brasileira" (LAJOLO. Monteiro Lobato: um brasileiro sob medida, p. 60). Por sua vez, Leonardo Arroyo, pioneiro nos estudos acadêmicos sobre literatura infantil, observa que Narizinho Arrebitado, a primeira história de Lobato, já "trazia toda uma série de valores temáticos e lingüísticos que renovava inteiramente o conceito de literatura infantil no Brasil". (ARROYO. Literatura infantil brasileira: ensaio de preliminares para a sua história e suas fontes, p. 198).
} 
o "País das Fábulas", onde os pica-paus encontram os fabulistas Esopo e La Fontaine e aproveitam para alterar algumas de suas histórias. Não só nesses momentos, mas também naqueles em que Dona Benta adapta para os netos alguns clássicos (como em Dom Quixote das Crianças, Peter Pan ou Hans Staden), os personagens do Sítio do Pica-pau Amarelo, de características tão ligadas à nossa cultura interiorana, tão nacionalizados, estão sempre em contato com outras culturas e com personagens de repertórios e tradições literárias diversificados.

Dessa forma, a obra infantil de Lobato acaba procedendo a uma carnavalização literária, ${ }^{2}$ mesclando vários repertórios e atualizando narrativas e personagens de tradições diversas. "País das Maravilhas", "País das fábulas" e "Mundo da Fábula" são noções semelhantes e flexíveis, pouco definidas, mas que compreendem, na obra de Lobato, tudo aquilo que seja ficcional e que possua características relacionadas ao fantástico e ao maravilhoso, elementos que são sempre evocados para caracterizar uma literatura adequada e interessante para crianças. Por isso, além de colocar em convivência com o conhecido núcleo do Sítio os personagens dos contos da carochinha, das histórias clássicas da literatura europeia, do cinema norte-americano, das Mil e uma noites e do folclore nacional, a obra de Lobato acaba se apropriando da mitologia grega, vista como um conjunto de narrativas que faria parte do "Mundo da Fábula". Histórias e personagens dessa mitologia são encontrados principalmente nas obras datadas do final da década de 1930 e do início da década de 1940: O Pica-pau Amarelo, O Minotauro e Os Doze Trabalhos de Hércules.

O Pica-pau Amarelo, de 1939, é a primeira obra em que se nota a forte presença dos mitos gregos. Nessa história ocorre a mudança de todos os personagens do "Mundo da Fábula" para o Sítio de Dona Benta, lugar onde, cansados da imobilidade dos antigos livros onde viviam, teriam mais liberdade para viver novas histórias. A narrativa da chegada desses personagens oferece uma boa dimensão da carnavalização literária e da miscelânea de tradições:

As condições foram aceitas e passada uma semana começou a mudança dos personagens do Mundo da Fábula para as Terras Novas de Dona Benta. O Pequeno Polegar veio puxando a fila. Logo depois, Branca de Neve com os sete anões. E as Princesas Rosa Branca e Rosa Vermelha. E o Príncipe Codadad, com Aladino, a Sheherazade, os gênios e todo o pessoal das Mil e uma noites. E veio a Menina da Capinha Vermelha. E veio a Gata Borralheira. E vieram Peter Pan com os Meninos Perdidos do "País do Nunca", mais o Capitão Gancho com o crocodilo atrás e todos os piratas; e a famosa Alice do "País das Maravilhas"; e o Senhor de La Fontaine em companhia de Esopo, acompanhados de todas as suas fábulas; e Barba-Azul com o facão de matar mulher, e o Barão de Münchausen com as suas famosas espingardas de pederneiras; e os personagens todos dos contos de Andersen e Grimm. Também veio Dom Quixote, acompanhado de Rocinante e do gordo escudeiro Sancho Pança. ${ }^{3}$

\footnotetext{
${ }^{2}$ A carnavalização literária é entendida, aqui, conforme a teoria exposta por Bakhtin (BAKHTIN. Problemas da poética de Dostoievski, p. 93.) sobre a transposição, para a literatura, do carnaval, espetáculo marcado pelas inversões simbólicas, pela quebra de convenções, pela excentricidade, pela profanação, pelo livre contato feito de forma familiar entre os diferentes e pela revogação temporária de todas as hierarquias, normas, leis e proibições.
}

${ }^{3}$ LOBATO. Histórias de Tia Nastácia. O Pica-pau Amarelo, p. 164. 
Logo em seguida, o narrador sugere que a mitologia grega também faria parte do "Mundo da Fábula":

A novidade maior foi a chegada dos personagens da mitologia grega - uma quantidade enorme! A Medusa, com aqueles cabelos de cobra - cada fio uma cobra, e atrás dela o valente Perseu que lhe cortou a cabeça. O Rei Midas, que só cuidava de amontoar ouro e acabou se enjoando. Os centauros, meio homens meio cavalos; e os faunos de chifrinhos; e os sátiros de pés de bode; e as sereias; e as ninfas; e as náiades, que eram as ninfas da água. ${ }^{4}$

A partir deste momento, os monstros e heróis da mitologia grega terão participação cada vez maior na trama, com destaque para a presença do herói Belerofonte, que, com o Pégaso e a Quimera já velha e caduca, se hospeda no sítio de Dona Benta, juntamente com Dom Quixote e Sancho Pança. Embora, em O Pica-pau Amarelo, toda a narrativa tenha como cenário o sítio de Dona Benta e as terras adjacentes a ele, esta é a primeira obra em que encontramos, em determinados momentos, trechos que denunciam uma valorização crescente da Grécia, sua mitologia e sua cultura, o que antecipa os temas das próximas aventuras, já que o seu desfecho fornece o gancho e o pretexto para as viagens do grupo do Sítio à Grécia antiga.

Nessa obra, inevitavelmente, a convivência entre personagens de origens tão distintas acaba criando conflitos ou situações inusitadas que conferem humor a determinadas passagens. Porém, durante a narrativa, ocorre um acidente com o mar da história de Peter Pan, pois a barragem que o sustentava se rompe e faz com que Branca de Neve se torne viúva, já que seu marido morre afogado. O grupo do Sítio tenta contornar esta situação e acaba articulando o casamento entre Branca de Neve com o Príncipe Codadad, das Mil e uma noites. Para isso, Emília faz uso de algumas flechas cedidas por Cupido. Porém, durante a festa de casamento, em que os mitos gregos constituem a maior parte da lista de convidados, ocorre uma invasão de monstros. Embora estes penetras sejam identificados apenas como "monstros fabulosos", nota-se que a lista se atém apenas aos monstros de origem grega:

Vinham todos, no galope, levantando nuvens de poeira. Dona Benta foi indicando os que conhecia. A Hidra de Lerna, a tal que havia descadeirado Dom Quixote. Briareu, o gigante de cinqüenta cabeças e cem braços. Bandos de centauros e faunos. Os ciclopes, gigantes de um olho só no meio da testa. Diomedes, feroz tirano da Trácia que alimentava os seus corcéis com a carne dos hóspedes. Os egipãs, metade homens, metade bodes. Encélado, o titã que procurou escalar o céu e caiu no fundo do vulcão Etna, derrubado por um raio de Júpiter. As Três Fúrias: Tisífona, Aleto e Mégera. Cérbero, o terrível buldogue que guardava as portas do Inferno. As Três Górgonas, de cabelos de serpentes. Pítia, a gigantesca serpente que lutou com Apolo. Vários hipogrifos: cavalos alados, com garras e caudas de dragão.

Vinha até a pobre Quimera, lá atrás de todos, manquitolando. ${ }^{5}$

Na confusão que se instaura com a invasão, Tia Nastácia, a cozinheira do Sítio, acaba raptada pelo Minotauro. Dessa forma, se a visita de Belerofonte configura o primeiro contato do núcleo do sítio com personagens oriundos da mitologia grega, o

\footnotetext{
${ }^{4}$ LOBATO. Histórias de tia Nastácia. O Pica-pau Amarelo, p. 165-166.

${ }^{5}$ LOBATO. Histórias de tia Nastácia. O Pica-pau Amarelo, p. 292.
} 
rapto que marca o desfecho da obra oferece um pretexto para que a próxima história de Lobato seja ambientada em algum lugar do mundo helênico, o que acontecerá em $O$ Minotauro, obra publicada em 1939.

Embora a motivação para a viagem à Grécia narrada em O Minotauro seja o resgate de Tia Nastácia no labirinto de Creta, os personagens do Sítio acabam realizando várias outras façanhas e participando de muitas outras aventuras em sua passagem pela Grécia mitológica, que vão desde uma consulta ao Oráculo de Delfos e à decifração do enigma da Esfinge em Tebas até uma sorrateira visita ao Olimpo para provar o néctar e a ambrosia.

Outro momento importante de O Minotauro é o trecho em que o grupo presencia uma das façanhas de Hércules, a luta contra a Hidra de Lerna, já que Os doze trabalhos de Hércules, publicado em 1944, consiste na narrativa da nova viagem feita pelos "pica-paus" à Hélade para assistir aos onze trabalhos restantes. Nessa obra, a mais extensa de toda a coleção infantil de Lobato, a narrativa de cada façanha é dividida, em geral, em seis ou sete capítulos. Porém, o trabalho em si, o enfrentamento de Hércules com os monstros ou com os desafios impostos, ocupa, em geral, apenas um único capítulo. Os outros são dedicados a narrar as viagens entre os diversos territórios da Hélade. Enquanto os personagens viajam e entram em contato com aspectos diversos da cultura grega, a obra cria oportunidades para que o grupo possa conviver com personagens de outras narrativas ou escutar, de outros personagens, narrativas de outros mitos gregos.

Tal presença de personagens e narrativas de origem helênica se mostra perfeitamente compreensível quando se nota, em trechos importantes da obra de Lobato, sua admiração pelos gregos antigos. Em relação a este aspecto, destacam-se alguns trechos de A barca de Gleyre, reunião das cartas enviadas por Lobato ao amigo Godofredo Rangel ao longo de quarenta anos. Esta correspondência continua sendo uma das principais fontes de pesquisa para os que estudam sua obra, pois nessas cartas Lobato muitas vezes explicita suas ideias e motivações em escrever para crianças, ao mesmo tempo que faz referências aos autores que lia e admirava, indicando, inclusive, aqueles que o teriam influenciado. As muitas referências aos gregos antigos sugerem a admiração de Lobato pela cultura helênica, como no momento em que o escritor registra as impressões de sua primeira leitura dos poemas homéricos. Em carta de fevereiro de 1908, Lobato, recém-formado em Direito, às vésperas do casamento e trabalhando como promotor público em Areias, no interior paulistano, explica ao amigo a demora em lhe escrever:

É provável que já me tenhas incluído entre os amigos de cruzinha na frente, e me suponhas lá pelo Lethes a disputar com Caronte. Errou. Estou mas é em Areias e a ler Homero. Só agora, neste interregno de 50 dias que me separam do casamento, e reentrado nesta calmaria absoluta de Areias, é que tive a oportunidade e mood de enfrentar o incomparável Homero - e lavo a alma das feias impressões do mundo moderno com este desfile sem fim de criaturas "belas como os deuses imortais".

Que diferenças de mundos! Na Grécia, a beleza; aqui, a disformidade. Aquiles lá; Quasímodo aqui. Esteticamente, que desastre foi o cristianismo com sua insistente cultura do feio!"

${ }^{6}$ LOBATO. A Barca de Gleyre, p. 207. 
Se o assunto do trecho é Homero, Lobato parece expressar sua admiração não só pela literatura, mas pela cultura grega em geral, cuja riqueza e vitalidade seriam contrapostas à "decadência" estética que, na sua visão, a ascensão do cristianismo teria trazido ao mundo ocidental. Passagens como essa nos ajudam a compreender por que Lobato mobiliza o repertório da mitologia grega em seu projeto de formação das crianças brasileiras, já que ela apresentaria um conteúdo enriquecedor que poderia ampliar as referências estéticas e culturais dos jovens leitores. Porém, apesar de toda admiração demonstrada por Homero, outros são os mitos gregos que se fazem presentes nas "aventuras helênicas" dos personagens de Lobato. Ao contrário do que acontece atualmente, em que temos uma profusão de edições da Ilíada e da Odisseia adaptadas para o público infantil, a obra de Lobato pouco se volta para as narrativas contidas nesses poemas, embora o escritor fosse deles um admirador.

Em O Pica-pau Amarelo, O Minotauro e Os doze trabalhos de Hércules, a presença da mitologia grega configura uma Grécia mitológica, representada como uma realidade histórica concreta, localizada no século XV a.C. e frequentemente nomeada como "Grécia Heroica”. Nesta Grécia, a presença marcante não é a de heróis da Ilíada, como Aquiles e Heitor que, num contexto de guerra entre "gregos e troianos", empreendem batalhas contra outros heróis. Se algum herói homérico se aproxima dos heróis de Lobato é Odisseu, que, na Odisseia, se encontra mais próximo de um determinado conteúdo primitivo ou teratológico, já que, em suas provações no retorno a Ítaca, se vê às voltas com o ciclope Polifemo, a bruxa Circe, a ninfa Calipso, os monstros marinhos Cila e Caribde e as sereias, além de descer aos infernos. Além disso, Odisseu representa um modelo de herói importante, pois resolve as dificuldades sempre com a esperteza, sendo polýtropos, multifacetado, o herói da métis por excelência, da inteligência ardilosa, que supera suas provações com a astúcia, o disfarce e a lábia, da mesma forma como os personagens de Lobato, em suas aventuras, superam os obstáculos ou os antagonistas. O próprio Lobato o nota quando, na carta seguinte àquela citada acima, indica suas preferências pela Odisseia:

Este mês de fevereiro foi o meu mês de Homero. Li a Ilíada e a Odisséia. Estou recheado de formas gregas, bêbedo de beleza apolínea. Maravilhoso cinema, Homero! Gostei muito mais da Odisséia. A Ilíada peca pelo inevitável monótono do tema - a guerra, ou antes, o combate. De começo a fim, gregos e troianos a morrerem como insetos, enquanto lá no Olimpo os divinos pândegos puxam os cordéis e intrigam. Diomedes, Ájax, Aquiles, Heitor, Sarpedo racham crânios, estripam ventres, fendem ombros, decepam cabeças, amolgam capacetes, rompem escudos, tomados duma horrível bebedeira de sangue. Aquiles é uma beleza. Páris, outra, mas de outro gênero. Já na Odisséia o assunto é caleidoscópico e sempre empolgante. Lê-se tudo aquilo como um romance de Maupassant. Penélope é ótima. Ulisses, um divino pirata. A descida aos "campos de asfódelos", deixa ver a origem da Divina Comédia. ${ }^{7}$

Se Lobato parece interessado no conteúdo heroico da mitologia grega, para a sua visão, mais interessante que a cólera de Aquiles em frente aos portões de Troia seriam os trabalhos de Hércules ou as façanhas de Belerofonte, Teseu e Perseu, heróis civilizadores

${ }^{7}$ LOBATO. A Barca de Gleyre, p. 208 e 209. 
que realizam grandes proezas ao enfrentar monstros e tiranos, pois é como se eles fossem responsáveis por levar a civilização a um outro estágio, eliminando o elemento escandaloso do mito.

A representação da "Grécia Heroica" enfatiza o aspecto primitivo da mitologia grega, onde o seu repertório é marcado pela variedade, pela vitalidade, pela riqueza, pela criatividade, pela "poesia" dos mitos. Assim, a obra de Lobato se apropria de personagens e mitos considerados mais interessantes para o público infantil, devido ao seu elemento fantástico e maravilhoso. Mas, além disso, este repertório estaria em acordo com a função que Lobato atribuía à mitologia de cada povo, conforme algumas das ideias expostas nos artigos que compõem a primeira fase de sua atuação na imprensa.

No decorrer da segunda metade da década de 1910, Lobato se profissionaliza como escritor quando começa a colaborar com O Estado de S. Paulo e, posteriormente, com a Revista do Brasil. Atuando como crítico de arte dos dois principais periódicos da imprensa paulista da época e em contato com vários intelectuais e escritores, Lobato passou a adotar uma postura nacionalista bem definida, elaborando um projeto para a arte, e para a cultura brasileira. Em textos dessa época, ele apresenta propostas para o desenvolvimento de uma arte nacional, distanciada da cópia dos modelos europeus e alimentada pelos diversos temas que poderiam ser encontrados na natureza, na sociedade ou na cultura popular brasileira.

Sua produção dessa época se encontra reunida em Ideias de Jeca Tatu, obra de 1917 que, de acordo com Tadeu Chiarelli, seria um testemunho do posicionamento de Lobato em relação à estética nacional. Analisando a primeira edição do livro, os textos que o compõem e a ordem em que foram dispostos no volume, este crítico nota que Lobato apresenta, conscientemente, um projeto bem definido e coerente para o desenvolvimento da arte nacional, que acaba expandido para outras áreas. Se, na primeira parte do livro, reúne seus textos sobre arte e arquitetura, na segunda apresenta textos que ampliam a preocupação com o nacional para outras áreas, como poesia, língua, cultura popular e história.

Em uma série de três textos publicados em janeiro de 1917, Lobato discute, a partir da noção de "estilo", as possibilidades que a postura nacionalista ofereceria para o desenvolvimento de uma estética nacional. Na sua visão, o "estilo" seria a marca de individualidade, a "feição peculiar das coisas. Um modo de ser inconfundível. A fisionomia. A cara."

Já em "Ainda o estilo", Lobato comenta a apropriação de elementos estrangeiros na arquitetura brasileira e afirma que não haveria nenhum povo "incapaz de fisionomia arquitetônica", porque isso seria "negar a grande lei biológica a que tudo se reduz: adaptação." O estilo se desenvolveria naturalmente, enraizado no que cada povo teria de mais particular. Nas suas palavras: "Os grandes estilos antigos, que assimilaram as grandes épocas históricas, desenvolveram-se como árvores, mergulhando raízes no solo." Para exemplificar suas ideias, Lobato cita povos que teriam criado estilos artísticos

\footnotetext{
${ }^{8}$ LOBATO. A Barca de Gleyre; LOBATO. A criação do estilo. In: LOBATO. Idéias de Jeca Tatu, p. 24.

${ }^{9}$ LOBATO. Ainda o estilo. In: LOBATO. Idéias de Jeca Tatu, p. 41.
} 
e arquitetônicos em sintonia com suas características culturais mais marcantes, como os egípcios, os russos, árabes, espanhóis, holandeses e, acima de todos, os gregos:

O estilo arquitetônico varia conforme o grau de inteligência, compreensão e sentimento artístico de cada povo. Nasce do solo como planta indígena, se o povo é criador e espontâneo como o grego. Na arquitetura grega nada grita em dissonância com o homem ou com a terra; jamais houve nada tão bem adaptado à paisagem envolvente, à índole da raça, aos seus usos e costumes, às suas necessidades, aos seus sentimentos e idéias. A simplicidade da vida, a formosura do tipo, a acuidade do pensamento, a frugalidade do povo eleito: - tudo sintoniza com a singela nobreza de seus sentimentos. ${ }^{10}$

$\mathrm{Na}$ visão de Lobato, o desenvolvimento do "estilo" seria um fato natural, determinado pela lei da evolução. No caso brasileiro, o "estilo" nacional estaria coibido pela artificialidade da cópia dos estilos estrangeiros por uma sociedade que reconheceria apenas padrões culturais europeus ou, mais especificamente, franceses. As "máscaras" importadas da Europa esconderiam a "matéria-prima" de que o Brasil dispunha para alimentar a produção artística e moldar sua própria cara: a natureza e a cultura popular, ricas em temas a serem apropriados pela arte.

A proposta de Lobato era que os motivos clássicos da arte e da arquitetura europeia fossem substituídos por temas genuinamente nacionais encontrados na cultura popular. $\mathrm{Na}$ arquitetura, o acanto, as colunas e cariátides de origem grega poderiam ser substituídos por equivalentes nacionais. Nas artes plásticas, a mitologia grega, tema recorrente na pintura acadêmica européia, poderia ser substituída por criaturas do folclore nacional, como a Iara ou o Saci, seres que fariam parte do conjunto que Lobato considerava a "mitologia brasílica":

Possuímos um satirozinho de grande pitoresco que ainda não penetrou nos domínios da arte, embora já se cristalizasse na alma popular, estilizado ao sabor da imaginativa sertaneja: o saci (...) Temos ninfas, ou o correspondente disso, puramente nossas; a Iara, a mãe d'água, a mãe do ouro. Temos caaporas, boitatás e tantos outros monstros cujas formas inda em estado cósmico nenhum artista procurou fixar. ${ }^{11}$

A mesma proposição se encontra em "A poesia de Ricardo Gonçalves”, em que Lobato repete sua apologia das criaturas criadas pela imaginação popular, em oposição aos anõezinhos do jardim da Luz:

Pelos canteiros de grama inglesa, há figurinhas de anões germânicos, gnomos do Reno, a sobraçarem garrafas de bier. Por que tais niebelungices, mudas à nossa alma, e não sacispererês, caiporas, mães d'água, e mais duendes criados pela imaginação popular? ${ }^{12}$

Já em "Como se forman lendas", Lobato conduz a discussão sobre a cultura popular a um outro nível. Considerando a "lenda" como uma manifestação vinculada ao "sonho", ela seria reveladora do que cada povo possui de mais específico, de mais introjetado em sua cultura. Em suas palavras, a lenda, existente em qualquer cultura, seria a "alma das

\footnotetext{
${ }^{10}$ LOBATO. Ainda o estilo. In: LOBATO. Idéias do Jeca Tatu, p. 37-38.

${ }^{11}$ LOBATO. A criação do estilo. In: LOBATO. Idéias de Jeca Tatu, p. 29-30.

${ }^{12}$ LOBATO. A poesia de Ricardo Gonçalves. In: LOBATO. Idéias de Jeca Tatu, p. 92-93.
} 
raças cristalizada pela tradição.", fosse ela criada por um "ilota de Atenas" ou por um "caipira de Areias". Descrevendo o caminho percorrido pelas lendas, Lobato afirma que elas são criadas pelo povo e depois estilizadas pelo artista, sendo a mitologia grega o maior exemplo de sintonia entre as lendas e os sentimentos do povo:

O lendário grego diz bem claro do povo que o concebeu. É bem filho dos marinheiros que borboletavam de ilha em ilha pelo Mediterrâneo, ao cair da noite metiam a nave em seco e dormiam descuidosos sob o tremelicar das estrelas, sonhando incomparáveis sonhos. A saúde dos homens, a formosura das mulheres, a lenidade do clima, o azul do céu, a vida livre e movimentada, criaram o ritmo daquela beleza - inexcedida na escultura e no sonho. ${ }^{13}$

Assim, a mitologia, na visão de Lobato, não é apenas mais um repertório ficcional fantástico do "Mundo da Fábula", mas uma base cultural em íntima consonância com o povo e, por isso, ponto de partida a partir do qual cada sociedade deveria se desenvolver. Nesse sentido, a Grécia aparece, ainda que pontualmente, como um exemplo de desenvolvimento cultural em Ideias de Jeca Tatu, em que Lobato deixa claro seu posicionamento sobre questões artísticas e culturais. Para ele, os gregos seriam um modelo histórico de concretização de seus ideais.

Em O Minotauro, o grupo de personagens do Sítio do Pica-pau Amarelo viaja também à cidade de Atenas no ano de 438 a.C., quando visitam a casa de Péricles, o Pireu, a Acrópole e o Partenón. Neste cenário, encontram e conversam com Péricles, Fídias, Aspásia, Sócrates, Sófocles, Heródoto, Policleto e Alcibíades. Neste diálogo com os gregos antigos, enfatiza-se a proeminência cultural daquele período não só em relação à história dos gregos como em relação à história da humanidade em geral. A pólis ateniense do século $\mathrm{V}$ a.C. é vista como uma Idade de Ouro, como o apogeu da cultura helênica e ocidental, onde, justamente, a mitologia teria um papel central, estando presente em suas principais manifestações: a arte, a arquitetura, o teatro, a política e a filosofia. Os gregos só teriam chegado a um patamar tão alto por terem utilizado sua mitologia como fonte de inspiração e de criação artística e cultural.

De um ponto de vista progressista ou evolucionista, sabe-se que, na Grécia da Antiguidade, poucas foram as inovações de caráter técnico. Mas, por outro lado, a sua cultura ainda hoje mantém a sua força e continua uma referência importante para todo o mundo ocidental. Nesse sentido, a história de Atenas no século V a.C. representa, para Lobato, um modelo de como seus ideais poderiam ser concretizados. Mesmo com pouco desenvolvimento tecnológico, os gregos, ou antes, os atenienses, teriam vivido uma Idade de Ouro.

Diante desta análise, torna-se possível compreender a presença da mitologia grega em algumas obras infantis de Lobato. Para ele, o caso helênico constituiria um exemplo histórico das possibilidades de progresso cultural nacional a partir dos elementos da cultura popular englobados sob o rótulo da "mitologia brasílica".

${ }^{13}$ LOBATO. Como se formam lendas. In: LOBATO. Idéias de Jeca Tatu, p. 108. 


\section{A B S TR A C T}

This article intends to show the several references to greek mythology in Monteiro Lobato's works for children and to comprehend the role of the appropriation of this repertory in the general frame of his work. Besides a important reference for education of young readers, greek mythology is seen as the basis from wich greek culture developed itself and achieved his apogee in the 5th. century B.C, offering an historical example of how brazilian culture could develop itself using brazilian mythology.

\section{KEYWORDS}

Monteiro Lobato, Greek mythology, Children's literature

\section{REFERÊNCIAS}

ARROYO, Leonardo. Literatura infantil brasileira: ensaio de preliminares para a sua história e suas fontes. São Paulo: Melhoramentos, 1968.

BAKHTIN, Mikhail. Problemas da poética de Dostoiévski. Trad. Paulo Bezerra. Rio de Janeiro: Ed. Forense-Universitária, 1981.

CHIARELLI, Tadeu. Um Jeca nos vernissages. São Paulo: EDUSP, 1995.

LAJOLO, Marisa. Monteiro Lobato: um brasileiro sob medida. São Paulo: Moderna, 2000.

LOBATO, Monteiro. A Barca de Gleyre. 4. ed. São Paulo: Brasiliense, 1951. v.I e II.

LOBATO, Monteiro. A reforma da natureza. O Minotauro. São Paulo: Círculo do Livro, 1984.

LOBATO, Monteiro. Idéias de Jeca Tatu. 7. ed. São Paulo, Brasiliense, 1956.

LOBATO, Monteiro. Os doze trabalhos de Hércules - I. São Paulo: Círculo do Livro, 1984.

LOBATO, Monteiro. Os doze trabalhos de Hércules - II. Histórias diversas. São Paulo: Círculo do Livro, 1984.

LOBATO, Monteiro. Reinações de Narizinho. São Paulo: Círculo do Livro, 1984.

LOBATO, Monteiro. Histórias de Tia Nastácia. O Pica-pau Amarelo. São Paulo: Círculo do Livro, 1984. 